\title{
Cartas de mães e pais de autistas ao Jornal do Brasil na década de 1980
}

José Augusto Leandro(a)

Bruna Alves Lopes ${ }^{(b)}$

Leandro JA, Lopes BA. Letters sent to the Jornal do Brasil by parents of autistic people during the 1980s. Interface (Botucatu). 2018; 22(64):153-63.

This paper analyzes a set of letters sent to the Jornal do Brasil by parents of autistic people during the 1980s. The text seeks to expand the knowledge of historical aspects of autism in the country through document research from printed media. It aims to highlight two key issues: that the correspondence published during that period expressed a variety of stances regarding the understanding of the autism phenomenon; and that the letters may be understood as expressions of advocacy by the concerned relatives who wanted to further stimulate actions focused on assistance for autistic people. The conclusion shows how mothers and fathers turned their parenting into political instruments.

Keywords: Autism. Letters. Jornal do Brasil. 1980s. Advocacy.
Este artigo analisa um conjunto de cartas escritas por mães e pais de autistas, publicadas no Jornal do Brasil na década de 1980. O trabalho busca contribuir, a partir de uma pesquisa documental realizada na imprensa periódica, com a ampliação de conhecimentos sobre aspectos relacionados à história do autismo no país. Objetiva demonstrar duas questões: que as correspondências publicadas no período expressaram variedade de posicionamentos em torno do entendimento do fenômeno do autismo; e que as cartas podem ser entendidas como expressões de advocacy de familiares interessados em ações de assistência aos autistas. Os resultados da pesquisa apontam para mães e pais transformando sua maternagem e paternagem em instrumento político.

Palavras-chave: Autismo. Cartas. Jornal do Brasil. Década de 1980. Advocacy.

\footnotetext{
(a,b) Programa de PósGraduação em Ciências Sociais Aplicadas, Departamento de História, Campus Uvaranas, Universidade Estadual de Ponta Grossa. Av. General Carlos Cavalcanti, 4748. Ponta Grossa, PR, Brasil. 84030-900. joseaugustoleandro@ gmail.com; bruna.hist.uepg@ gmail.com
} 


\section{Introdução}

No Brasil, o ano de 2012 foi marcado pela aprovação da lei no $12.764^{1}$, também conhecida como lei Berenice Piana. Com ela, os autistas passaram a ser reconhecidos legalmente como pessoas com deficiência, sendo-lhes garantidos e assegurados direitos antes não existentes: acesso à educação e ao ensino profissionalizante; mercado de trabalho; à previdência e assistência social; e acesso a ações e serviços de saúde, o que incluiu aspectos tais como o direito ao atendimento multiprofissional, à terapia nutricional e o acesso a medicamentos.

A lei no 12.764 baliza os contornos contemporâneos da história da cidadania da pessoa autista. Resultado de uma longa caminhada, a consecução de direitos para os autistas no Brasil está relacionada diretamente ao engajamento de seus familiares a partir da década de 1980. Neste decênio, marcado pela conjuntura da transição do regime ditatorial-militar para o regime liberal-democrático ${ }^{2}$, com ampliação da mobilização de distintos setores da sociedade civil, mães e pais de autistas trouxeram à tona suas angústias sobre a condição de seus filhos, utilizando-se de meios de comunicação, como jornais impressos.

No artigo que segue, demonstramos que as correspondências, escritas por mães e pais de autistas, enviadas ao Jornal do Brasil (JB) na década de 1980 não ilustram apenas meros desabafos acerca das dificuldades do gerenciamento da vida cotidiana de seus filhos. As cartas podem ser entendidas como reveladoras de um determinado conhecimento - nem sempre unívoco - do fenômeno do autismo naquele momento; e, ademais, apontamos que as correspondências expressam o potencial da escrita como advocacy ${ }^{(c)}$ sobre o tema da assistência aos autistas. $^{3}$

\section{Sobre o autismo e a emergência do engajamento da família no debate do tema, no Brasil: a importância da década de 1980}

Desde meados da década de 1940, com os estudos de Leo Kanner e Hans Asperger, o termo autismo começou a ser utilizado como expressão de uma entidade diagnóstica relacionada a dificuldades na interação social, na qual a comunicação e o aprendizado do indivíduo tornam-se diferenciados ${ }^{4}$. Por volta dos três anos de idade, ou mesmo antes, percebe-se que o comportamento da criança em relação ao mundo social é mais voltado ao distanciamento do que ao agrupamento e aproximação em relação aos que a cercam. Cavalcante ${ }^{5}$ descreve que a "[...] falta de contato com as pessoas, repetitividade obsessiva da mesmice, presença de elaborados rituais e rotinas, fixação em preocupações estranhas, direcionadas e intensas eram os principais sinais observados por Kanner" (p. 302) ${ }^{(d)}$.

Paralelamente aos primeiros estudos psiquiátricos do autismo na década de 1940, também floresceu o interesse de outros profissionais acerca do fenômeno, destacando-se os vinculados à psicanálise. Klin ${ }^{6}$ anotou que "durante os anos 50 e 60 do século passado, houve muita confusão sobre a natureza do autismo e sua etiologia, e a crença mais comum era a de que o autismo era causado por pais não emocionalmente responsivos a seus filhos (a hipótese da 'mãe geladeira')" (p. 4). Dentre os autores que discorreram sobre o fenômeno do autismo nesse campo, destacou-se o austríaco Bruno Bettelheim, radicado nos Estados Unidos. Em sua obra mais conhecida, A fortaleza vazia, de 1967, Bettelheim definiu o autismo como uma resposta da criança a um ambiente hostil criado por pais frios e distantes, ou seja, não amorosos.

Hoje, a neurologia e a genética estão sempre presentes quando se tenta definir o autismo, como se vê na passagem de Assumpção Júnior e Kuczynski:

\author{
(c) Entende-se que \\ advocacy diz respeito \\ a " [...] defender e \\ argumentar em favor \\ de uma causa, uma \\ demanda ou uma \\ posição. Isso porque \\ advocacy tem um \\ significado mais \\ amplo [que advogar], \\ denotando iniciativas de \\ incidência ou pressão \\ política, de promoção \\ e defesa de uma causa \\ e/ou interesse, e de \\ articulações mobilizadas \\ por organizações da \\ sociedade civil com \\ o objetivo de dar \\ maior visibilidade a \\ determinadas temáticas \\ ou questões no debate \\ público e influenciar \\ políticas visando à \\ transformação da \\ sociedade" ${ }^{3}$ (p. 208)
}

\footnotetext{
(d) Para Grinker, “[...] se Kanner é o pai do autismo como distúrbio diagnosticável, Asperger é o pai do autismo como espectro de diferentes estados". O antropólogo afirma: "A característica mais importante das crianças com distúrbio de Asperger é não ter dificuldades na fala [...]. Contudo, ainda assim têm muitas dificuldades para comunicar-se e interagir socialmente [...]"4 (p. 71).
} 
"um transtorno do desenvolvimento neurológico complexo e altamente hereditário, caracterizado pelo evidente comprometimento da função cognitiva no campo da interação social e do desenvolvimento da fala"7 (p.28).

Apesar de as ideias de Bettelheim sobre a culpa dos pais no desencadeamento do autismo terem repercutido, sobretudo, em países em que a psicanálise era influente, como na França, por exemplo ${ }^{4}$, já na primeira metade da década de 1960, nos EUA, emergiram questionamentos sobre as explicações de base psicogênica ${ }^{8}$. Quanto a isso, cabe destacar a relevância do livro Infantile Autism: The Syndrome and Its Implication for a Neural Theory of Behavior, de autoria do psicólogo Bernard Rimland, pai de uma criança autista. A obra, publicada originalmente em 1964, é apontada como a primeira a considerar o autismo como um distúrbio essencialmente neurológico ${ }^{8-10}$.

O trabalho de Rimland foi fundamental para a criação, em 1965, da National Society for Autistic Children (NSAC) ${ }^{9}$, entidade criada por familiares de crianças autistas, e que se caracterizou como um espaço de especialização em autismo. Eyal e Hart ${ }^{10}$ argumentam que a NSAC colaborou para uma compreensão do fenômeno a partir de conhecimentos construídos em rede, numa parceria entre pesquisadores, terapeutas e familiares; estes últimos passaram a ser reconhecidos e valorizados como sujeitos com expertise no autismo, ao lado dos profissionais da saúde. Nas palavras de Eyal e Hart: "a NSAC funcionou como um ponto de encontro para que os pais aprendessem uns com os outros, para que experimentassem e relatassem diferentes modalidades terapêuticas, criando circuitos de acumulação de conhecimento fora das revistas profissionais" (p. 15).

Poucos são os autores que abordam a história do autismo e do engajamento de mães e pais de autistas no Brasil. Fátima Cavalcante ${ }^{5}$ destacou a construção da Associação de Mães de Autistas (AMA), em 1983, e caracterizou essa associação como "a primeira 'cara' do autismo" no que diz respeito ao ativismo político sobre o tema no país (p. 340) ${ }^{5}$. Observou que embora, desde a década de 1930, existissem no Brasil algumas instituições privadas especializadas na área da deficiência mental (como a Sociedade Pestalozzi, de 1932), e, posteriormente, as APAEs, surgidas a partir de 1962, o campo do autismo representava "uma grande lacuna e uma ampla inexistência de recursos especializados que começam a se estruturar, de modo ainda incipiente, a partir da década de 1980 [...] (p.333).

Destaque-se, também, o trabalho realizado por Fernanda Nunes ${ }^{9}$, que discute o processo de politização da experiência e atuação política de familiares de autistas no Rio de Janeiro, realizando um trabalho etnográfico em três instituições fluminenses - Associação de Pais de Autistas e Deficientes Mentais (APADEM), de 1999, Mundo Azul, de 2011, e Pelo Direito dos Autistas, de $2012^{(\mathrm{e})}$ reconhecidas, nacionalmente, por sua militância em prol do tema do autismo. A autora acompanhou a série de mobilizações que tiveram como objetivo a sansão da lei $n^{\circ} 12.764 / 2012$.

A história do papel da família na mobilização política pela construção de uma agenda proativa no campo da assistência para o autismo segue como um relevante tema de investigação no Brasil. Assim como Cavalcante observou que a década de 1980 foi importante no país pela criação das primeiras AMAS em São Paulo, também enfatizamos a importância deste decênio como marco significativo para uma reflexão histórica sobre o início do engajamento da família para um melhor conhecimento da questão do filho autista.

Um conjunto de cartas enviadas a um jornal de uma grande metrópole brasileira tem muito a nos dizer sobre advocacy e autismo. Para além da sua quantidade, apenas 13, cremos que a importância desses documentos reside no fato de que eles expressaram aspectos qualitativos semelhantes concernentes à 
vivência de centenas de mães e pais de autistas no Brasil daquele momento, em suas buscas de um melhor bem-estar para os seus filhos.

\section{Material e métodos: sobre as fontes da pesquisa}

A pesquisa empreendida contou com o suporte virtual da Hemeroteca Digital da Biblioteca Nacional (http://hemerotecadigital.bn.br). A partir do acionamento das ferramentas de busca do site (pesquisa por periódico, período e local), delimitamos a investigação para a década de 1980 no Jornal do Brasi( ${ }^{(f)}$, utilizando-se o termo "autismo".

O JB foi o veículo escolhido para a pesquisa não apenas pela sua ampla circulação em boa parte do território nacional à época estudada, mas, também, porque acompanhou, de maneira privilegiada, o processo de redemocratização do país operado a partir do final da década de 1970, permitindo que suas páginas expressassem anseios de diferentes grupos naquele contexto ${ }^{11}$.

Do total de 72 ocorrências do termo pesquisado, foram identificadas 13 correspondências enviadas ao JB, publicadas na seção "Cartas", em sua maioria com o título "Autismo". Duas foram publicadas no ano de 1983, duas em 1984, uma em 1986, três em 1987, duas em 1988 e três em 1989. Oito delas foram escritas por mulheres, das quais quatro apresentaram-se, ao público leitor do jornal, enquanto mães de crianças autistas; três se identificaram como representantes de alguma associação ligada ao autismo ${ }^{(\mathrm{g})}$, e uma como representante da Legião Brasileira de Assistência (LBA). Entre os homens, das cinco cartas enviadas, em uma delas não há identificação alguma acerca da condição de quem escreveu; um deles representou o Instituto Nacional de Assistência Médica da Previdência Social (INAMPS), e, nas demais cartas, os homens se apresentaram como membros de alguma associação, sem explicitar se eram pais de autistas. Pressupomos, excluindo o representante do INAMPS e a representante da LBA, que todos os demais escreveram na condição de pais ou mães de autistas. Portanto, as cartas evidenciam os vínculos parentalidadeautismo e/ou instituição-autismo como estimuladores da escrita e do envio de correspondência ao JB.

Segundo Lobo ${ }^{12}$, apesar da liberdade de imprensa no país ter ocorrido oficialmente em 1978 - tendo como um dos resultados o fim da censura prévia aos jornais impressos - até o final do governo do general João Baptista Figueiredo, em 1985, os meios de comunicação vivenciavam aquilo que a autora denominou de "liberdade vigiada". Apesar disso, tal situação possibilitou maior liberdade para se tratar de temas candentes naquele momento, como: as reformas políticas e partidárias, a anistia e as eleições diretas, embora os jornais ainda carecessem de ampla liberdade no trato das palavras impressas. Nesse sentido, "[...] o Jornal do Brasil esteve sobre uma corda bamba [...], desempenhando papel destacado na formação da opinião pública sobre os rumos da abertura política"12 (p. 1).

Santo $^{13}$ faz considerações sobre o significado das cartas enviadas a jornais, e afirma que elas podem ser tomadas " [...] como instrumentos de transmissão de informação sobre a vida em sociedade", uma vez que "[...] fazem parte de um processo discursivo e estão inseridas em condições sócio-históricas". Nas palavras da autora:

Páginas e colunas específicas para sua publicação servem como espaços de denúncia, de confronto do político/social, de reivindicação, de

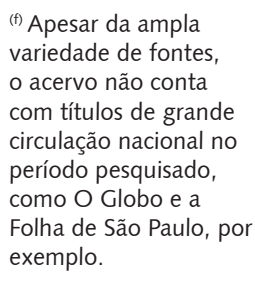

(g) Uma das cartas foi elaborada por três mulheres, todas representando a mesma instituição. 
desabafo, enfim, de exercício da cidadania. Há que se considerar ainda que aqueles que escrevem representam uma população muito mais ampla que se possa dimensionar porque, no fundo, são uma espécie de porta-voz das queixas e observações de tantos/as outros/as que, por algum motivo, não enviam suas opiniões aos jornais. Dessa forma, as cartas [podem ser] analisadas como produto de uma interação social que reflete o pensamento de um grupo que deseja se informar e se comunicar em determinado contexto social, histórico e ideológico ${ }^{13}$. (p. 14)

Em outro momento, Santo, juntamente com Dumont ${ }^{14}$, afirma que o jornal pode ser visto como "[...] um meio dialógico, mesmo que registre certo desequilíbrio entre as vozes que o constroem" (p. 179), pois possibilita o contato de pessoas com experiências e visões de mundo distintas, viabilizando a comunicação entre elas.

Esses apontamentos nos auxiliaram no entendimento de que a seção "Cartas" do JB, da década de 1980, constituiu um espaço em que o leitor se colocou não apenas como receptor passivo do discurso produzido e divulgado pelo jornal, mas, pelo contrário, ali também residiu a possibilidade de mães e pais de autistas agirem como produtores de discursos, não somente seus, mas, também, de um determinado grupo. Como sugeriu Epstein ${ }^{15}$ para o HIV/AIDS - e isso também pode ser pensado para outros casos, como transtornos, síndromes e deficiências, por exemplo - as batalhas em torno da credibilidade do conhecimento acerca da doença passaram por uma variedade de vozes: não apenas a dos cientistas, mas incluíram outras, como a dos familiares que também se lançaram como membros ativos na discussão do fenômeno, acionando, inclusive, a mídia para a desconstrução de estigmas e preconceitos até então sedimentados. A politização da epidemia, segundo ele, trouxe consequências benéficas, uma vez que resultou na multiplicação das vias de sucesso para o estabelecimento de credibilidade e diversificação de pessoas para atuar sobre a doença, além do grupo da saúde já qualificado para isso ${ }^{15}(p$. 3). No nosso caso aqui analisado, o JB foi fonte privilegiada para se buscar verificar aspectos positivos da interface advocacy, mídia e saúde na construção de uma agenda para o autismo no país na década de 1980.

\section{Resultados e discussão}

\section{As cartas e o entendimento do autismo}

A análise das cartas demonstrou que a maioria das mães e dos pais alocou o fenômeno do autismo em um espaço de 'doença', com ênfase em aspectos 'desconhecidos'. Na primeira carta identificada na pesquisa, de 1983, uma mãe sugeriu que o autismo poderia, inclusive, ser fruto de problemas que atingiriam o bebê durante o parto, ou, até mesmo, resultado da administração de fortes medicamentos em recém-nascidos. O fenômeno expressaria

[...] uma doença de etiologia desconhecida, mas de natureza comprovadamente orgânica, que apresenta grande incidência em crianças que foram vítimas de anoxia, excessiva oxigenação ou doses abusivas de antibióticos por ocasião do nascimento. $01^{\circ}$ sintoma é o balançar rítmico da cabeça e do corpo, desde o berço, seguindo-se total abstração do mundo exterior, que a criança simplesmente parece ignorar, aparentemente sem audição, preferindo concentrar-se horas seguidas brincando com seus próprios dedos [...]. Suas vítimas são fisicamente sadias, ágeis, bonitas e sem qualquer expressão que denote doença, pelo que são frequentemente tidas como surdas. $^{16}$ (p. 10)

A mesma argumentação acerca do caráter enigmático das causas do autismo foi registrada em correspondência de 1984, quando a mãe de um menino de sete anos de idade descreveu o fenômeno de seu filho como um "obscuro distúrbio"17 (p. 10). Os substantivos 'deficiência', 'enfermidade', 'mal' e 'doença' também foram utilizados nos documentos, ao lado do adjetivo 'grave' para caracterizar o autismo nas cartas da década de 1980. Em 1989, pela primeira vez, o termo 'síndrome do autismo' foi anotado em correspondência escrita por uma mãe. 
As expressões sobre autismo destacadas nas cartas refletem um período em que o Brasil estava, ainda de maneira incipiente, descobrindo e debatendo publicamente as ocorrências do fenômeno. Castela ${ }^{18}$ argumenta que, ao longo da década de 1980, o conceito de autismo foi ampliado, e isso contribuiu para que ele deixasse de ser visto como uma doença, para ser considerado uma síndrome. Além disso, o autismo também deixou de ser apresentado como um distúrbio afetivo para ser considerado um distúrbio do desenvolvimento.

Mesmo assim, ainda no final da década, havia dissenso sobre o tema. Em novembro de 1988, em carta ao JB, um pai definiu o autismo como um 'sintoma' da esquizofrenia infantil ${ }^{19}$. Diante disso, a Associação de Pais de Autistas do Rio de Janeiro (APARJ), fundada em 1985, veio a público criticar fortemente a definição do autismo enquanto um sintoma da esquizofrenia. Em correspondência ao periódico, a entidade manifestou-se dizendo ser

... errônea [a] informação contida na carta Autismo (JB, 3/11/88) e que só contribuiu para criar confusão e aumentar a desinformação sobre 0 problema. [...]. As últimas pesquisas desenvolvidas nos EUA, com auxílio da tomografia computadorizada por ressonância magnética, revelam a presença de deformações anatômicas no cerebelo, o que pode ser o responsável pela falta de respostas aos estímulos externos manifestada pelos portadores deste mal. Autismo não tem nada a ver com esquizofrenia infantil, que só surge depois dos dois anos e apresenta sintomas diversos. ${ }^{20}$ (p. 10)

Além dos embates ao redor do conceito de autismo, foram recorrentes, nas cartas enviadas pelos pais e mães, as dificuldades em se conseguir o diagnóstico da síndrome, situação destacada já em 1983.

Eu tenho a infelicidade de ter uma filha autista, cujo mal só foi diagnosticado ao ver o filme acima mencionado [Meu filho, meu mundo], o que me levou a contactar o Dr. Rimland do Institute Child Behavior Research, maior autoridade no assunto, que me forneceu literatura e orientação para o tratamento, que exige inclusive controle do metabolismo. ${ }^{16}$ (p. 10)

Quanto ao filme "Meu Filho, Meu Mundo"(h), chamou a atenção de muitos pais sobre a possibilidade de seus filhos serem autistas. Participantes da APARJ, inclusive, não ficaram nada satisfeitos quando um crítico de filmes exibidos na televisão classificou-o como "dramalhão" menor, dentro do estilo "destino cruel" 21 (p. 4). A partir da seção "Cartas", do Caderno B, um dos membros da associação utilizou tal espaço para questionar os comentários feitos acerca da produção cinematográfica. Na percepção do então vice-presidente da APARJ, faltou sensibilidade e conhecimento sobre o autismo para o crítico de cinema. Em suas palavras:

O referido filme não se trata de um dramalhão, mas sim de um excelente material de apoio a exemplificar sintomas e estereotipias do autismo. [...] conhecemos vários casos de pais que após sucessivas buscas em meios ditos especializados só conseguiram o diagnóstico de autismo após assistirem ao filme. ${ }^{22}$ (p. 36) (h) O filme Meu filho, meu mundo (título original Son-Rise: A Miracle of Love), lançado em 1979, retrata a história de uma família cujo filho caçula é diagnosticado como autista. 
(1) Embora existisse desde 1983, nenhuma das cartas mencionou a AMA

(Associação de Amigos do Autista), criada por pais de autistas residentes em São Paulo.
Se, no período analisado, houve divergência entre mães e pais acerca do entendimento da origem do fenômeno do autismo, todos compartilhavam, em seus discursos, um aspecto fundamental: urgia chamar a atenção da sociedade para a necessidade de ações assistenciais aos autistas.

\section{As cartas e a (ausência de) assistência aos autistas}

A ausência de instituições especializadas no atendimento aos autistas foi tema de destaque nas cartas enviadas ao JB. Já no primeiro documento identificado pela pesquisa, em 1983, uma mãe teceu comentários críticos sobre as entidades para pessoas com deficiência no país, afirmando que as existentes ${ }^{(i)}$ :

...[misturavam] anarquicamente todos os tipos de males, como

oligofrenia, mongolismo, esquizofrenia [...]. O meu propósito ao

escrever esta carta é conclamar a todos os pais que sofrem este mesmo angustiante problema em suas famílias, a me contatarem, para reunirmos esforços e conseguirmos criar uma instituição voltada para a pesquisa e tratamento do autismo, para o bem de nossos filhos ${ }^{16}$. (p. 10)

Em virtude de uma resposta a esta carta de 31 de outubro, muitas famílias tiveram a oportunidade de saber da existência de um estabelecimento chamado Centro de Educação Especial Casarão, fundado em 1978, no Rio de Janeiro, que atuava em prol da assistência aos autistas. A carta-resposta apresentou, rapidamente, o trabalho desenvolvido no Casarão, e também frisou a necessidade de que novas entidades semelhantes tivessem a atenção dos órgãos governamentais, pois trabalhos nesta área demandavam "custos muito elevados" 23 (p. 10).

Em 1984, outra carta enviada por uma mãe também relatou dificuldades enfrentadas devido à falta de instituições especializadas no atendimento de autistas no Rio de Janeiro. Segundo a narrativa, a Legião Brasileira de Assistência (LBA) não estava aceitando "[...] casos como o do meu filho por não verem perspectivas de melhoras e cura"17. Antes de se mudarem para a capital fluminense, mãe e filho moravam em Minas Gerais, e um certo atendimento assistencial era feito pela LBA daquele estado. Tal atendimento significou, nas palavras da mãe, "um período de êxitos e melhoras". O texto da carta foi de cobrança, inclusive financeira, afirmando que a entidade dispunha de dinheiro para a assistência destinado pela verba da Loteria Esportiva ${ }^{17}$.

Tal mãe obteve uma carta-resposta da representante da LBA do Rio de Janeiro, publicada no JB no dia 06 de janeiro de 1984. A então presidente da Legião escreveu:

Quanto à pergunta sobre a "verba" da Loteria Esportiva que seria destinada à LBA, devo acrescentar que, desde 1975, pela lei $n^{\circ} 6.168$ de 09/12/74, a LBA não foi mais contemplada sequer com a renda de um teste anual. Nossos atuais recursos são oriundos, exclusivamente, do Ministério da Previdência e Assistência Social e é com eles que estamos realizando uma programação social $\left[\ldots . .{ }^{24}\right.$ (p. 10)

No final da década analisada, em 1989, uma mãe escreveu ao JB dizendo-se surpreendida pelo fato de que, ao final do século $X X$, a sociedade ainda estivesse despreparada para o trato com as pessoas deficientes "[...] e em especial ao autista, pois no Brasil muito pouco ou quase nada se sabe sobre esta doença" 25 ( $p$. 
10). Segundo ela, " $[\ldots .$.$] as últimas estatísticas comprovam que temos atualmente no país cerca de 200$ mil crianças autistas". A mãe enfatizou que "[...] o que não sabemos de fato [é] se estas crianças estão efetivamente bem assistidas e amparadas". Ela colocou-se "[...] à disposição para divulgar a experiência pedagógica que [vinha] implementando com o [seu] filho com considerável êxito [...]"25 (p. 10).

Dois anos antes da publicação desta carta, o JB estampou, no dia 18 de agosto de 1987, no caderno 'Ciência', uma matéria intitulada "Diagnóstico de Autismo confunde os médicos". Tal matéria foi publicada em decorrência da vinda, ao Brasil, do médico estadunidense Edward Ritvo, especialista em autismo ${ }^{26}$. Nas páginas do jornal, abordou-se uma das principais controvérsias em relação ao tema, sua origem orgânica ou psicológica. Além disso, destacou-se a falta de profissionais especializados na área capazes de realizar um diagnóstico mais preciso, e a escassez de instituições especializadas no atendimento de autistas no país.

A publicação do caderno 'Ciência' foi de fundamental importância para a APARJ, associação fundada em 1985 por pais e mães de crianças autistas que moravam na cidade do Rio de Janeiro. Não apenas pelo fato de ajudar na divulgação do evento da palestra do Dr. Ritvo, patrocinada pela APARJ, mas, também, para que outros pais pudessem tomar conhecimento da existência da própria associação. Um representante da APARJ enviou uma carta ao JB agradecendo pela reportagem publicada.

Como consequência imediata do evento e da reportagem publicada, estamos recebendo centenas de telefonemas de adesões e de pais que identificaram autismo em seus filhos [...]. Já recebemos comunicação do presidente do INAMPS de que os autistas passarão a receber diagnóstico e atendimento, o que até então não ocorre. [...] A palestra do dr. Ritvo está sendo impressa, para distribuição, em todo território nacional, o que também será muito importante, por difundir os conhecimentos atualizados do problema ${ }^{27}$. (p. 10)

Quanto ao atendimento dos autistas pelo INAMPS do Estado do Rio de Janeiro, uma carta enviada ao JB, em setembro de 1987, pelo representante da coordenação do Grupo de Saúde Mental daquele instituto, apontou que algumas medidas positivas estavam sendo tomadas pelo órgão naquele momento, e que poderiam auxiliar na futura assistência dos autistas. Entre elas, destacou o apoio financeiro para o desenvolvimento de uma linha de pesquisa e atendimento ao autista em parceria com o Instituto de Psiquiatria da Universidade Federal do Rio de Janeiro ${ }^{28}$.

Ao que tudo indica, 1987 foi pródigo em ações de advocacy de pais e mães de autistas no estado do Rio de Janeiro. Pressionar pelo suporte financeiro e material do INAMPS foi a principal estratégia adotada por eles naquele ano. Em carta enviada ao JB por uma mãe de Nova Iguaçu, publicada em 17 de setembro daquele ano, deu-se conta de informar aos leitores que uma comissão de mães de autistas, encaminhada pela deputada Heloneida Stuart, havia comparecido a uma audiência com o Sr. Presidente do INAMPS para que fosse implantado, naquela rede, "[...] tratamento específico para pessoas acometidas de autismo". A carta finalizou destacando a necessidade de que essas primeiras providências do órgão assistencial não sofressem "descontinuidade", para que, brevemente, fosse possível "[...] implantar no país um tratamento adequado ao autista" 29 (p. 10).

Importante destacar que, concomitantemente ao processo de redemocratização do país ao longo da década de 1980, houve um frutuoso debate envolvendo profissionais da saúde e variados movimentos sociais em torno da modificação e da ampliação do conceito de saúde, atribuindo-lhe uma dimensão política, ligada ao próprio acesso à assistência e aos serviços em saúde ofertados pelo Estado. O período foi marcado por uma intensa mobilização de setores da sociedade civil em torno de pautas ligadas à saúde. A VIII Conferência Nacional de Saúde, ocorrida em 1986, foi um marco discursivo para o atendimento universal. Buscava-se "romper com a cisão estrutural entre saúde pública e medicina curativa individual, e com a intensa privatização que então caracterizava o sistema de saúde brasileiro" 30 (p. 241). O Sistema Único de Saúde (SUS) nasceu nesse contexto e, a partir da Constituição de 1988, seguiu os princípios da universalidade, equidade e integralidade. O SUS rompeu com a lógica do antigo INAMPS, cuja dinâmica de atendimento em saúde era voltada para o auxílio aos que contribuíam para a previdência social, excluindo todo o resto da população inserida na informalidade do mercado de trabalho. 


\section{Considerações finais}

Ao escreverem para o $\mathrm{JB}$, pais e mães de autistas produziram sentido sobre o que consideravam ser o autismo, com ênfase no fenômeno como 'doença obscura'. Se, por um lado, a própria definição do autismo naquele período foi objeto de divergências entre os que enviaram cartas ao jornal, por outro lado, os pais foram unívocos ao apontarem: a necessidade da divulgação do tema do autismo, as dificuldades de obtenção de diagnósticos mais precisos para seus filhos e a ausência de instituições especializadas para a assistência aos autistas.

Se as cartas expressaram necessidades de ações de advocacy em relação ao autismo, também é possível afirmar que o próprio jornal foi um instrumento de advocacy no período analisado. O JB agiu na construção e transmissão de informações relacionadas à saúde e, ao seu modo, possibilitou a vocalização de proposições de familiares de autistas. Desta forma, num cenário de democratização da política brasileira de modo geral, e da agenda de saúde em particular, o JB pode ser apontado como um importante exemplo dos aspectos positivos da interface advocacy, mídia e saúde.

Nas relações de forças que envolvem o discurso ${ }^{31}$, muitos pais perceberam que o JB, enquanto um veículo de ampla circulação nacional e de grande impacto no estado do Rio de Janeiro, teria forte influência na formação de opinião de leitores. Isso é perceptível ao se verificarem as respostas às cartas enviadas, fato que indica que as correspondências eram acompanhadas atentamente por uma comunidade de leitores interessados no tema. Muito provavelmente, as instituições Centro de Educação Especial Casarão e APARJ passaram a ser conhecidas por inúmeros pais de crianças autistas, uma vez publicadas as correspondências que faziam menção ao trabalho desenvolvido por elas.

Pelas cartas analisadas, é possível alinhar-se ao sugerido por Fernanda Nunes. Em seu estudo, elaborou uma distinção entre ser pai/mãe de um autista e ser um pai/mãe ativista, sendo que, no segundo caso, a experiência de paternagem e maternagem se transforma num ato político. Nas palavras da autora, o tornar-se um pai/mãe ativista "[...] envolve largo processo de expertise política, aprendizagem de termos médicos, técnicos, legislativos e jurídicos, assim como de trâmites burocráticos e negociações junto a vereadores, deputados, senadores e ministros"9 (p. 42).

As correspondências de mães e pais de autistas publicadas na década de 1980 no JB certamente representaram uma população muito mais ampla de interessados no tema, e podem ser lidas como ilustrativas da experiência de paternagem e maternagem transformando-se num ato político. As cartas enviadas ao jornal foram instrumentos fundamentais na construção de redes de interesses comuns entre familiares de autistas. Essas redes continuam até os dias de hoje, com diferentes linguagens e suportes tecnológicos, agregando novas pautas ao tema do autismo.

\section{Colaboradores}

Leandro e Lopes foram responsáveis pela idealização e redação do artigo. O texto é parte das pesquisas de tese de Doutoramento de Lopes, que conta com a orientação de Leandro. 


\section{Referências}

1. Presidência da República (BR). Casa Civil. Lei n 12.764, de 27 de dezembro de 2012. Institui a Política Nacional de Proteção dos Direitos da Pessoa com Transtorno do Espectro Autista. Diário Oficial da União. 28 Dez 2012 [citado 26 Jan 2016]. Disponível em: http://www.planalto.gov.br/ccivil_03/_ato2011-2014/2012/lei/l12764.htm.

2. Codato AN. Uma história política da transição brasileira: da ditadura militar à democracia. Rev Sociol Polit [Internet]. 2005 [citado 26 Jan 2016]; 25:83-106. Disponível em: http://www.scielo.br/scielo.php?script=sci arttext\&pid =S0104-44782005000200008.

3. Libardoni M. Fundamentos teóricos e visão estratégica da advocacy. Rev Estud Fem. 2000 [citado 15 Abr 2015]; 8(2):207-21. Disponível em: https://periodicos.ufsc.br/index. $\mathrm{php} / \mathrm{ref} /$ article/view/11936/11202.

4. Grinker RR. Autismo: um mundo obscuro e conturbado. São Paulo: Larousse do Brasil; 2010.

5. Cavalcante FG. Pessoas muito especiais: a construção social do portador de deficiência e a reinvenção da família. Rio de Janeiro: Fiocruz; 2003.

6. Klin A. Autismo e síndrome de Asperger: uma visão geral. Rev Bras Psiquiatr. 2006 [citado 20 Mar 2015]; 28(1):3-11. Disponível em: http://www.scielo.br/pdf/rbp/v28s1/ a02v28s1.pdf.

7. Assumpção Júnior F, Kuczynski E. Autismo infantil: novas tendências e perspectivas. São Paulo: Atheneu; 2015.

8. Silverman C, Brosco JP. Understanding autism: parents and pediatricians in historical perspective. Arch Pediatr Adolesc Med. 2007; 161(4):392-9.

9. Nunes FCF. Atuação política de grupos de pais de autistas no Rio de Janeiro: perspectivas para o campo da Saúde [dissertação]. Rio de Janeiro (RJ): Universidade do Estado do Rio de Janeiro; 2014.

10. Eyal G, Hart B. How parents of autistic children became experts on their own children: notes towards a sociology of expertise. Berkeley J Sociol. 2010 [citado 11 Nov 2016]. Disponível em: https://works.bepress.com/gil_eyal/1/.

11. Ribeiro B. Jornal do Brasil, história e memória. Rio de Janeiro: Record; 2015.

12. Lobo CSL. Na corda bamba - o Jornal do Brasil em tempos de abertura (1978-1985) [Internet]. In: Anais do XI Encontro Regional de História: Democracia e Conflito; 2004; Rio de Janeiro, Brasil. Rio de Janeiro: Associação Nacional de História (ANPUH); 2004. p. 1-10 [citado 10 Mar 2015]. Disponível em: http://www.rj.anpuh.org/conteudo/ view?ID_CONTEUDO $=305$.

13. Espírito Santo P. O que informam as cartas de leitores e leitoras enviadas a jornais impressos: os casos do Estado de Minas e do Le Monde [tese]. Belo Horizonte (MG): Universidade Federal de Minas Gerais; 2012 [citado 26 Jan 2016]. Disponível em: http:// www.bibliotecadigital.ufmg.br/dspace/bitstream/handle/1843/ECID-8XNKCT/pati_1_. pdf?sequence $=1$.

14. Espírito Santo P, Dumont LMM. As cartas de leitores e leitoras enviadas a jornais impressos: o que querem informar os assinantes do jornal Estado de Minas. Perspect Cienc Inf. 2014 [citado 26 Jan 2016]; 19(2):174-90. Disponível em: http://www.scielo.br/pdf/ pci/v19n2/13.pdf.

15. Epstein S. Impure science: AIDS, activism and the politics of knowledge. Berkeley: University of California Press; 1996.

16. Rocha SAS. Autismo. Jornal do Brasil. 31 Out 1983. p. 10.

17. Brandão OC. Autismo secundário. Jornal do Brasil. 02 Jan 1984. p. 10. 
18. Castela CA. Representações sociais e atitudes face ao autismo [dissertação]. Faro, Portugal: Universidade do Algarve; 2013.

19. Moreira MS. Autismo. Jornal do Brasil. 03 Nov 1988. p. 10.

20. Rocha PP. Autismo. Jornal do Brasil. 25 Nov 1988. p. 10.

21. Fortes PA. Um tremendo baixo astral. Jornal do Brasil. 29 Jun 1986. p. 4.

22. Coelho E. Filme na TV. Jornal do Brasil. 20 Jun 1986. p. 36.

23. Leon LMP, Akerman P, Bastos T. Autismo e psicose. Jornal do Brasil. 06 Nov 1983. p. 10.

24. Leal L. Drama da mãe. Jornal do Brasil. 06 Jan 1984. p. 10.

25. Cunha MRRM. Autismo. Jornal do Brasil. 25 Ago 1989. p. 10.

26. Silva E. Diagnóstico de autismo confunde os médicos. Jornal do Brasil. 18 Ago 1987. p. 7.

27. Rocha PP. Autismo. Jornal do Brasil. 30 Ago 1987. p. 10.

28. Villano LAB. Autismo. Jornal do Brasil. 01 Set 1987. p. 10.

29. Silva M. Autismo. Jornal do Brasil 17 Set 1987. p. 10.

30. Falleiros I, Lima JCF, Matta GC, Pontes ALM, Lopes MCR, Morosini MVC, et al. A Constituinte e o Sistema Único de Saúde. In: Ponte CF, organizador. Na corda bamba de sombrinha: a saúde no fio da história. Rio de Janeiro: Fiocruz/COC; 2010. p. 239-78.

31. Orlandi EP. Análise de discurso: princípios e procedimentos. Campinas: Pontes; 2001.

Leandro JA, Lopes BA. Cartas de madres y padres de autistas al Jornal do Brasil en la década de 1980. Interface (Botucatu). 2018; 22(64):153-63.

Este artículo analiza un conjunto de cartas escritas por padres y madres de autistas, publicadas en el Jornal do Brasil en la década de 1980. El objetivo del trabajo es contribuir, a partir de un estudio documental realizado en la prensa periódica, para la ampliación de conocimientos sobre aspectos relacionados con la historia del autismo en el país. Su objetivo es demostrar dos puntos: que las correspondencias publicadas en el período expresaron variedad de posicionamientos sobre el entendimiento del fenómeno del autismo y que las cartas pueden entenderse como expresiones de advocacy de familiares interesados en acciones de asistencia a los autistas. Los resultados del estudio señalan a padres y madres que transforman su maternidad y paternidad en instrumento político.

Palabras clave: Autismo. Cartas. Jornal do Brasil. Década de 1980. Advocacy. 
